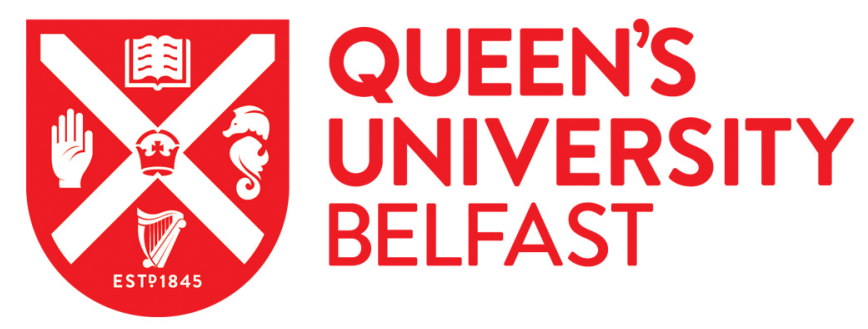

\title{
Production of biowaste granules and their evaluation as adsorbent for removal of hexavalent chromium and methylene blue dye
}

\author{
Jaiyeola, O. O., Chen, H., Albadarin, A., \& Mangwandi, C. (2020). Production of biowaste granules and their \\ evaluation as adsorbent for removal of hexavalent chromium and methylene blue dye. Chemical Engineering \\ Research and Design, 164, 59-67. https://doi.org/10.1016/j.cherd.2020.09.020
}

Published in:

Chemical Engineering Research and Design

Document Version:

Peer reviewed version

Queen's University Belfast - Research Portal:

Link to publication record in Queen's University Belfast Research Portal

Publisher rights

(c) 2020 Published by Elsevier B.V. on behalf of Institution of Chemical Engineers.

This manuscript version is made available under the CC-BY-NC-ND 4.0 license http://creativecommons.org/licenses/by-nc-nd/4.0/,which permits distribution and reproduction for non-commercial purposes, provided the author and source are cited.

\section{General rights}

Copyright for the publications made accessible via the Queen's University Belfast Research Portal is retained by the author(s) and / or other copyright owners and it is a condition of accessing these publications that users recognise and abide by the legal requirements associated with these rights.

Take down policy

The Research Portal is Queen's institutional repository that provides access to Queen's research output. Every effort has been made to ensure that content in the Research Portal does not infringe any person's rights, or applicable UK laws. If you discover content in the Research Portal that you believe breaches copyright or violates any law, please contact openaccess@qub.ac.uk. 


\title{
Production of bio-waste granules and their evaluation as adsorbent for removal of hexavalent chromium and methylene blue dye
}

\author{
Oluwafikayo O. Jaiyeola ${ }^{1}$, Haili Chen ${ }^{1}$, Ahmad B. Albadarinn ${ }^{2,3}$ and Chirangano Mangwandi*1 \\ ${ }^{1}$ School of Chemistry and Chemical Engineering, Queen’s University Belfast, Stranmillis Road, Belfast BT6 \\ 8JA, United Kingdom. \\ ${ }^{2}$ Department for Management of Science and Technology Development, Ton Duc Thang \\ University, Ho Chi Minh City, Viet Nam \\ ${ }^{3}$ Faculty of Applied Sciences, Ton Duc Thang University, Ho Chi Minh City, Viet Nam
}

E-mail c.mangwandi@qub.ac.uk

\begin{abstract}
In this research, compost was used as raw materials in the production of biomass adsorbent granules using drum granulation technique. Different concentrations of aqueous sodium silicate solution were used as the binding agents. Chromium and Methylene Blue solutions were selected as model adsorbates for heavy metals and dyes, respectively. The results obtained showed that the concentration of sodium silicate used had a positive influence on the mechanical strength of the granules, increasing the concentration would increase the compressive strength of the granules. The adsorbent granules had sufficient strength to survive wet conditions they were subjected during the adsorption study. However, increasing the concentration has a negative influence on the adsorption properties of the compost granules for both Chromium and Methylene Blue.
\end{abstract}

\section{Keywords}

Sodium silicate; drum granulation; adsorbent; chromium; methylene blue; cationic dye;bio-waste 


\section{Introduction}

Wet granulation is a size enlargement process that has received attention in several industries such as mineral processing, detergents, pharmaceuticals, chemical and fertiliser industries. During the wet granulation process, different kinds of equipment, such as fluidised bed, rolling discs, drum granulator and high shear granulators, are used to supply rolling, tumbling or shear forces to raw starting materials and finally form loose agglomerates (also called granules) with the addition of liquid binders. Recently, the wet granulation technique for biomass agglomeration has attracted worldwide attention to make different granular products such as fuel materials, soil conditioners or fertilisers [1$10]$.

To the best of our knowledge that there has been no study of the production of biomass granules as an adsorbent for heavy metal removal. Adsorption as a separation process is widely applied in the manufacturing economy and everyday life. Adsorption performance is strongly influenced by mass transfer of the species between the solution and the adsorbent surfaces and also the adsorption reaction rate. In carrying out adsorption studies, a good contact between adsorbent and the liquid solution which need to be treated is fundamental. Therefore, for adsorbent granules, the selection of the binder remains a crucial step as the binder has to be relatively stable and keep the shape of the adsorbent granules in aqueous solution at least for the duration of the adsorption process.

So far, different binders have been reported to make biomass granules. Using the starch - sodium alginate as a binder to make switchgrass granules was reported by Yandapalli and Mani [8]. Also, Bowden-Green and Briens used the hydroxypropyl methylcellulose solution as a liquid binder for granulation of biochar powders[11]. Furthermore, Ghasemi et al. produced the compost granules using sugar beet molasses as binders [1, 2]. Among these reports, organic binders are commonly used for biomass agglomeration. Recently, in our research group, Chen et al. produced the compost granules by using inorganic silicate-based binders and the produced granules had a good ability of water resistance[12]. It was reported that the silicate-based binders do offer higher performance in strength and water resistance of agglomerates [13], for the adsorption process, such water resistance ability can offer significant advantages over the other water-soluble binders.

Therefore, in this study, we focused on the investigation of (1) using different concentrations of inorganic silicate-based binders for the production of compost granules through a drum granulation process and also (2) evaluating the produced granules as potential adsorbents for removal of heavy 
metals and dyes using chromium and methylene blue (a basic cationic dye) as model adsorbates, respectively.

\section{Experimental method}

\subsection{Adsorbent granule production}

Granules that were produced in our previous work were used in this study[12]. Briefly, the granules are produced from biomass material (using compost as model biomass) in a drum granulator with a length of $0.65 \mathrm{~m}$ and an internal diameter of $0.38 \mathrm{~m}$. 300 grams of the biomass material was granulated with a sodium silicate solution as the binder. The biomass material was sieved through a $2.8 \mathrm{~mm}$ mesh sieve. The average size of the particles was about $1.4 \mathrm{~mm}$. The liquid to solid ratio and rotational speed of the drum was kept constant at 0.77 and $37 \mathrm{rpm}$ respectively whereas the concentration of sodium silicate was varied from 0 to $9 \%(\mathrm{w} / \mathrm{w})$. The granulation time was also kept constant at 15 minutes. For more details please see reference [12]. The batches will be named using this nomenclature SX where $\mathrm{X}$ is percentage concentration of sodium silicate in the binder so for example for batch produced with a 3\% sodium silicate binder the batch or sample ID will be S3 whereas if no sodium silicate was in the binder it will be referred to as S0. After granulation and drying of the granules, the granules were characterised in terms of size distribution, strength, and product yield and water resistance. More details on the analysis can be found in ref [12].

\subsection{Batch Adsorption Studies}

All experiments for initial testing were carried out at room temperature $\left(24 \pm 2{ }^{\circ} \mathrm{C}\right)$ using $0.05 \mathrm{~g}$ of compost in a beaker containing $20 \mathrm{~mL}$ of $\mathrm{Cr}(\mathrm{VI})$ and $20 \mathrm{~mL}$ methylene blue solution with appropriate concentration. Depending on the particular experiment being studied, batch adsorptions were carried out at the desired $\mathrm{pH}$ value, contact time, and adsorbent dosage level. $1 \mathrm{~mL}$ of the chromium solution was taken and added to $9 \mathrm{~mL}$ of water. $6 \mathrm{ml}$ of the resultant solution was taken and added to $2 \mathrm{~mL}$ of a reagent (1 5-diphenylcarbazide). The solution was analysed using a U-V spectrophotometer at a wavelength of $540 \mathrm{~nm}$. For methylene blue, the solution was analysed at a wavelength of $668 \mathrm{~nm}$. The absorbance values were used to determine the concentration of the solutions using the appropriate calibration constants. The amount of sorbed $\mathrm{Cr}$ (VI), qe, was calculated in $\mathrm{mg} \mathrm{g}^{-1}$ according to,

$q_{\mathrm{e}}=\frac{(\mathrm{Co}-\mathrm{Ce})}{m} * \mathrm{~V}$

The removal percentage of $\mathrm{Cr}$ (VI) was calculated according to, 
$\mathrm{R}=\frac{(\mathrm{Co}-\mathrm{Ce})}{\mathrm{Co}} * 100$

In equations (5) and (6) $\mathrm{Ce}_{\mathrm{e}}, \mathrm{C}_{0}, \mathrm{~V}$ and $\mathrm{m}$ are residual concentration in solution, co is initial concentration, mass of adsorbent and solution volume respectively.

Previous adsorption studies of chromium and $\mathrm{MB}$ show that the optimum $\mathrm{pH}$ are 2 and 10 respectively $[14,15]$. For the isotherm studies, chromium solution of $\mathrm{pH} 2$ was used and a mass of $0.05 \mathrm{~g}$ of compost was weighed out and used in a beaker with $20 \mathrm{ml}$ of the chromium solution. Different concentrations of chromium were used for the test (25, 50, 75, $100 \mathrm{ppm})$. For the isotherm analysis of methylene blue, a pH solution of 10 was used and a mass of $0.05 \mathrm{~g}$ of compost was weighed out and used in a beaker with $20 \mathrm{ml}$ of the methylene blue solution of the methylene blue dye. $1 \mathrm{~mL}$ of the chromium solution was taken and $9 \mathrm{~mL}$ of water added. $6 \mathrm{ml}$ of the resultant solution was taken and added to $2 \mathrm{~mL}$ of a reagent (1 5-diphenylcarbazide). There was no need for a reagent for methylene blue, just the dilution factor of 10 was considered. The solution was analysed using a U$\mathrm{V}$ spectrophotometer to calculate the absorbance and ultimately the concentration of chromium and methylene blue concentrations and the subsequent removal.

For the adsorption kinetics study, 100ml solutions of chromium and methylene blue were used and $0.25 \mathrm{~g}$ of the compost material was used to test for the rate constant, the $\mathrm{pH}$ for each of the solutions was kept at 2 and 10 respectively, different temperatures were used from ( 25 to $60^{\circ} \mathrm{C}$ ) and an agitation speed of 150rpm for 1 week were the conditions for the rate constant test. Samples were taken at different intervals and a dilution factor of 10 was used for both solutions. All granules used in the adsorption studies were in the size range 4.75 to $6.7 \mathrm{~mm}$.

\section{Results and discussion}

\subsection{Size Analysis}

The granulation experiments were a success and granules produced were all spherical with size going up to $15 \mathrm{~mm}$. Figures 1 (a) shows the size distributions of granules as the concentration of the sodium silicate binder increases, as can be seen from the plot the peak of the plots shift to the left as the amount of sodium silicate in the binders is increased, meaning the average size of the batches decreases with increasing binder concentration. The median size of each sample is given in Figure 1(b). It is clear from Figure 1 (b) that the granule median size decreases as the sodium silicate is introduced into the formulation for instance addition of just $1 \%$ of the silicate results in median size decreasing from $6.72 \mathrm{~mm}$ to $\sim 5 \mathrm{~mm}$, a further increase of the binder concentration to $5 \%$ results in a 
reduction in granule median size a factor of 3 . The yield of the granules decreased with increasing concentration of the sodium silicate in the binder. The viscosity of the binder increases as the concentration of sodium silicate increases as shown in Figure 2 (a). Whether the size of the granules decreases or increased with increasing binder concentration depends on the dominating growth mechanism under the given conditions. The observed decrease in the size of the granules with increasing binder concentration could be due to changes in the deformability of the granules as the concentration of the binder was changes as previously reported $1.4 \mathrm{~mm}$ [12]. Increasing the concentration of silicate in the binder increased with viscosity of the binder solutions which in turn reduced the mobility of the binder thereby limiting the amount of binder available at the nuclei surfaces. The reduction in the deformability limit granule growth by coalescence. Similar observations were made during the drum granulation of biochar powder with hydroxypropyl methylcellulose (HPMC) binder solution in recent work[11].

The yield of the granule in the desire size range was also negatively impacted by the introduction of sodium silicate into the formulation. As can be seen in Figure 2 (b) increasing the composition of sodium silicate result in a lower yield of granules for example batches where the binder concentration was $3 \%$ had product yield of about $60 \%$ compared to $50 \%$ for the $5 \%$ formulation and $90 \%$ when there is not sodium silicate in the binder solution.

\subsection{Strength and water stability analysis}

Even though the overall granule median size decreases with the increasing silicate concentration as discussed in the preceding sub-section, it is interesting to note that presence of the silicate in the formulation has a positive influence on the dry granule strength. Increasing the concentration of the sodium silicate increased strength of the granule exponentially as shown in Figure 3(a). This can be attributed to the silicate forming more strong solid bridges between the primary particles as it solidifies, the higher the binder concentration the more bonds are formed hence the greater the strength of the granules formed which is agreement previously reported in the literature $[7,16]$. Since the granules are to be used for the adsorption under aqueous conditions it was also imperative to check their stability of in the water. The goal of this work was to produce granules that would not disintegrate in aqueous conditions. To this end, the granules were soaked in water and their strength analysed and the results are presented in Figure 3(b). As can be seen from Figure 3(b) there was a significant reduction in the strength of the granules after soaking them in water for a 24hour period, however, the granules remained intact as can be seen Figure 3 (a) and (b). 
However, it was noted that there was a noticeable slight change in the colour of the water which may be attributed to leaching of some compounds for the granules and this was not pronounced for the S3 granules.

\subsection{Adsorption Studies}

\section{Biomass granules as adsorbent of chromium (VI)}

The results from the trial adsorption of chromium (VI) on to the four different types of granules are presented in Figure 5. As can be seen in Figure 5, the removal of chromium by the compost granules was successful, between 95 and 98 \% removal achieved with 100 ppm solution using a dosage of 2.5 g/ L. The adsorption capacity of the granules ranged from 0.732 to $0.754 \mathrm{mmol} \mathrm{Cr} / \mathrm{g}$. The highest removal was obtained when granules without sodium silicate (S0) was used. The granules with sodium silicate achieve slightly less removal ranging from 95 to $97 \%$ and a negative correlation between the sodium silicate concentration and the adsorption capacity and percentage removal of chromium. However, there was an insignificant difference between the removal capacity of S0 and S1 granules though further increase in concentration beyond 1\% results in a marked decrease in the adsorption capacity of the granules. However, it is worth noting the adsorption capacity of the four samples of granules analysed here are comparable to those reported in the literature $[7,15,17,18]$.

\subsection{Biomass granules as adsorbent of methylene blue dye.}

Figure 5 (c) and (d) show results from adsorption of the model dye methylene blue. The results are based test done using methylene solution with an initial concentration 100 ppm solution with an adsorbent dosage of $2.5 \mathrm{~g} / \mathrm{L}$. As can be seen from Figure 5(c) the percentage removal ranged from about $69 \%$ to about $91 \%$. Similar to results for chromium removal, the removal decreased with increasing concentration of sodium silicate in the granules and same applies to the adsorption capacity. However, the loss of adsorption capacity between the S0 and S5 samples was about 23\% compared to $3 \%$ in the case capacity towards chromium removal. The adsorption capacity of the granule with respect of MB reported $39 \mathrm{mg} / \mathrm{g}$ is comparable to values reported in previous work [14, 15, 19-21].

The decrease in the adsorption capacity with increasing sodium concentration in the binder may be attributed to the coverage of the pores of the primary particles making up the composite granule as the silicate forms a glassy layer during the bond formation process. Besides the porosity of the granule results (See Figure 2(a)) was found to decrease with increasing sodium silicate concentration. This 
makes the pores inaccessible to adsorbate molecules during the adsorption process thereby reducing the capacity of the granules. This effect is more pronounced when the adsorbate involved is a large molecule as is the case with methylene blue molecule. In the adsorption of $\mathrm{MB}$, the presence of the silicate could also be altering the $\mathrm{pH}$ of the solution creating condition which are less conducive for adsorption of MB which favours alkaline conditions.

\subsection{Isotherm Analysis}

Adsorption isotherm studies are important to define the fraction of adsorbate molecules that are divided between solid and liquid phases at equilibrium. In the current study, the isotherm results were examined using the Langmuir and Freundlich isotherm models. The Langmuir isotherm model can be written as [15]:

$q_{e}=\frac{q_{m} b C_{e}}{1+b C_{e}}$

Where $\mathrm{q}_{\mathrm{m}}$ and $b$ are the Langmuir constants related to maximum monolayer adsorption capacity and energy of adsorption, respectively. The values of $\mathrm{q}_{\mathrm{m}}$ and $b$ were calculated and presented in (Table $1)$.

The Freundlich isotherm is the other empirical model which is commonly used to describe adsorption data. The Freundlich isotherm is expressed by the following equation[15]:

$q_{e}=k_{f} C_{e}^{\frac{1}{n}}$

Where, $k_{f}$ and $n$ are the Freundlich adsorption constants.

Non-linear regression was used to obtained parameters of Langmuir and Freundlich models using a custom-built code written in MATLAB and these are presented in Table 1. For chromium, the Langmuir parameters whilst for methylene blue the Freundlich parameters are reported. It can be noticed from Table 1 that there is a general decrease in the Langmuir adsorption capacity for the chromium as the concentration of sodium silicate in the granules increases as observed in the preliminary adsorption studies. The data presented in Table 1 and Figure 6 show that the Langmuir model fit the chromium model best, whilst the Freundlich model fit the Methylene blue dye best. 


\subsection{Adsorption Kinetics}

The adsorption kinetics can be evaluated using pseudo $1^{\text {st }}$ order kinetics equation which is written as[22]:

$$
q(t)=q_{e}\left[1-\exp \left(-k_{1} t\right)\right]
$$

where $q(t)$ is the amount of adsorbed solute at time $t, q_{e}$ its value at equilibrium, and $k_{1}$ the pseudofirst-order rate constant.

According to Ho and McKay if the sorption process is $2^{\text {nd }}$ order chemisorption, the sorption rate can be expressed by the equation[23]:

$$
\frac{d q_{t}}{d t}=k_{2}\left(q_{e}-q_{t}\right)^{2}
$$

In Eq. (10) $q_{e}$ and $q_{t}$ are sorption capacity at equilibrium and at a time t respectively and $k_{2}$ is the rate constant of the pseudo order. Integrating the equation and using the boundary conditions of $q_{t}=$ 0 at $t=0$ and $q_{t}=q_{t}$ at $t=t$ will result in the following equation:

$$
\frac{1}{\left(q_{e}-q_{t}\right)}=1+k_{2} q_{e} t
$$

It can be shown that Eq. (11) can expressed as

$$
q_{t}=\frac{k_{2} q_{e}^{2} t}{1+k_{2} q_{e} t}
$$

The results from the kinetics study of the uptake of $\mathrm{Cr}(\mathrm{VI})$ and methylene blue dye onto the compost granules performed at different temperatures with different granule samples were evaluated by nonlinear regression of Eq. (9) and (12) using a custom-built MATLAB program and the results are presented in Table 2. The removal kinetics for both chromium (VI) and methylene blue dye are presented in Figures 7 (a) and (b) and Figure 7 (c) and (b) respectively. The rate of removal chromium removal is higher at the beginning, this is largely due to the larger surface area of the compost being available at the beginning for the adsorption of metals. With time, the surface adsorption sites become exhausted where at this point, the uptake rate can be regarded to be controlled by the rate at which the adsorbate is transported from the exterior to the interior sites of the adsorbent particles. It can be 
noticed from Figure 7 that increasing temperature has a significant effect on the amount of adsorbate uptake for both $\operatorname{Cr}(\mathrm{VI})$ and MB. For instance, after a contact time of 2 hours amount of $\operatorname{Cr}(\mathrm{VI})$ increases by 6 fold from $0.02 \mathrm{mmol} / \mathrm{g}$ to $0.12 \mathrm{mmol} / \mathrm{g}$ when system temperature is increased from $26^{\circ} \mathrm{C}$ to $60^{\circ} \mathrm{C}$. Also as observed in other studies the initial rate of adsorption is considerably increased by increasing the temperature[24]. The summary of the kinetics parameters obtained from non-linear regression is presented in Table 2. The data shows that both models can be applied to describe the kinetics of the removal of chromium (VI) and methylene blue as there is no significant difference in the goodness of fit.

\subsection{Thermodynamic studies}

The temperature dependency of adsorption can be described by the Arrhenius equation which is written as:

$k=A * \exp \left(-\frac{E_{a}}{R T}\right)$

where $E_{a}$ is the activation energy ( $\left./ \mathrm{mol}\right), k$ is the rate constant of adsorption, A is Arrhenius factor, which is the temperature-independent factor, $R$ is the universal gas constant $(\mathrm{J} / \mathrm{K} \mathrm{mol})$, and $T$ is the solution temperature $(\mathrm{K})$. Non-linear regression fit of equation 14 to the kersus $\mathrm{T}$ data is shown in Figure 8 and the obtained activation energies for adsorbent granules are reported in Table 3.

As can be seen from the plots presented in Figure 8 were as the adsorption kinetics of chromium is not significantly different for the two types of granules. However, that is not the case with the removal of methylene blue dye, the difference in the performance of the granules becomes more significant at higher temperatures in comparison to lower temperatures. The activation energy for the removal of MB dye is by the S0 granules is almost twice that of S3 granules. The activation energies of both the S0 and S3 adsorbent granules during removal of chromium are both higher than $40 \mathrm{~kJ} / \mathrm{mol}$ (about 56 $\mathrm{kJ} / \mathrm{mol}$ ) which would suggest the removal is due to chemisorption as they are higher than the typical values for physisorption process which ranges between 6 and $16 \mathrm{~kJ} / \mathrm{mol}$ [15, 25]. The difference in the activation energy for the binding of chromium and methylene blue ions does indicate that the ions are going through different processes in binding.

\subsection{Thermodynamic parameters}

To evaluate the nature and mechanism of biosorption MB and chromium on the granule surface, the biosorption date at different temperatures were used to calculate the thermodynamic parameters 
namely change in enthalpy $(\Delta \mathrm{H})$, change in entropy $(\Delta \mathrm{S})$ and change in Gibbs free energy $\Delta \mathrm{G}$, using eq. (15), (16) and (17):

$\Delta G=-R T \ln \left(55.5 \times K_{d} x 1000\right)$

$\Delta G=\Delta H-T \Delta S$

$\ln \left(55.5 x K_{d} x 1000\right)=\frac{\Delta S}{R}-\frac{\Delta H}{R T}$

where $R$ is the universal gas constant $(8.314 \mathrm{~J} / \mathrm{mol} \mathrm{K})$. The term $55.55\left(\mathrm{~mol} / \mathrm{dm}^{3}\right) \times k_{d}$

$\left(\mathrm{dm}^{3} / \mathrm{mmol}\right) \times 1000$ is dimensionless. $K_{d}=\frac{\mathrm{q}_{\mathrm{e}}}{\mathrm{c}_{\mathrm{e}}}$ where qe and $\mathrm{ce}_{\mathrm{e}}$ are as defined previously.

The enthalpy $\Delta \mathrm{H}$ and entropy $\Delta \mathrm{S}$ associated with adsorption are obtain from the slope and the linear plot of $\ln K d$ versus $1 / \mathrm{T}$.

The estimated thermodynamics parameters; change in free Gibbs energy $(\Delta \mathrm{G})$, change in enthalpy $(\Delta \mathrm{H})$ and change in entropy $(\Delta \mathrm{S})$ for the removal of $\mathrm{Cr}(\mathrm{VI})$ and MB by S0 and S3 adsorbent granules are presented in Table 3. As can be seen from the table the change in enthalpy values are all positive for both the removal of $\mathrm{Cr}(\mathrm{VI})$ and $\mathrm{MB}$ by the adsorbent granules which imply endothermic removal processes. The relatively high enthalpy values for the removal of MB by the adsorbent granules are indicative of strong bond formation between the MB molecules and the functional groups on the compost granules. Similar endothermic sorption of methylene blue on palm kernel fibre[26], date pit [27], and neem leaf powder[28] have been reported in the literature. The small positive $\Delta S$ values suggested an increase in the randomness at the solid/solution interface for both the adsorption of $\mathrm{Cr}(\mathrm{VI})$ and MB on the S0 and S3 adsorbent granules. For the removal of Cr(VI), the Gibbs free energy values decrease with increasing temperature suggesting that the spontaneity of the process increases with increasing temperature which is a similar trend observed in literature in a study of the biosorption removal of Cr(VI) by chemical modified date pit [27]. For the biosorption of Cr(VI), the free energy values are negative at higher temperatures indicating thermodynamically feasible and spontaneous nature of the adsorption process. At the same temperature, the $\mathrm{S} 3$ granules the $\Delta \mathrm{G}$ values are slightly lower than the corresponding values for S0 granules.

\subsection{Comparison with other materials}

Comparison of the chromium removal capacity of the compost granules with other different adsorbent materials reported in the literature[7, 17, 18, 24, 27, 29-32] is presented in Table 4. In the same table list of other materials used for removal of methylene blue dye is also provided [26, 28, 33-35]. It can be noted that the compost granules have comparable removal capacity for both $\mathrm{Cr}(\mathrm{VI})$ and $\mathrm{MB}$. 


\section{Conclusion}

This work investigated the feasibility of using granules produced from compost by drum granulation as adsorbent material for removal of heavy metals and dyes via adsorption. It can be concluded that compost granules have great potential for use as an absorbent material and have adsorption capacity that is comparable to other adsorbent material. The results show that the addition of sodium silicate enhances the strength of the granules however will reduce the adsorption capacity the granules. If the composite granules are to be used as an adsorbent for chromium or methylene, it is recommended the concentration of the sodium silicate should be limited to $1 \%$ as adding anything more than $1 \%$ will reduce the performance of the granule. The kinetic studies denoted that the adsorption of chromium and methylene blue ions onto compost material followed the pseudo-second-order model and the equilibrium data fitted well with Freundlich isotherm model for methylene blue and Langmuir isotherm model for chromium. The thermodynamics results showed that the adsorption of chromium and methylene blue ions onto compost material was spontaneous and the reaction was endothermic. Currently, desorption of the ions from the material to be reused for adsorption is being studied and further analysis would be provided in the future. 


\section{REFERENCES}

1. Ghasemi, Y. and M.H. Kianmehr, The effect of filling of the drum on physical properties of granulated multicomponent fertilizer. Physicochemical Problems of Mineral Processing, 2016. 56: p. 575-587.

2. Ghasemi, Y., et al., The effect of rotational speed of the drum on physical properties of granulated compost fertilizer. Physicochemical Problems of Mineral Processing, 2013. 49: p. 743-755.

3. Iakovleva, E., et al., Application of Al2O3 modified sulfate tailings (CaFe-Cake and SuFe) for efficient removal of cyanide ions from mine process water. Minerals Engineering, 2018. 118: p. 24-32.

4. Iakovleva, E., et al., Manufacturing of novel low-cost adsorbent: Co-granulation of limestone and coffee waste. Journal of Environmental Management, 2017. 203: p. 853-860.

5. Mangwandi, C., et al., Development of a value-added soil conditioner from high shear co-granulation of organic waste and limestone powder. Powder Technology, 2014. 252: p. 33-41.

6. Mangwandi, C., et al., High shear granulation of binary mixtures: Effect of powder composition on granule properties. Powder Technology, 2015. 270: p. 424-434.

7. Martín-Lara, M.A., et al., Simultaneous biosorption of methylene blue and trivalent chromium onto olive stone AU - Trujillo, M.C. Desalination and Water Treatment, 2016. 57(37): p. 17400-17410.

8. Yandapalli, V. and S. Mani, Wet granulation of pine wood powders. American Society of Agricultural and Biological Engineers. , 2014. 57: p. 1211-1218.

9. Yandapalli, V. and S. Mani, Effect of lime pretreatment on granulation of switchgrass. Bioenergy Research, 2014. 7: p. 833-844.

10. Mangwandi, C., et al., An investigation of the influence of process and formulation variables on mechanical properties of high shear granules using design of experiment. International Journal of Pharmaceutics, 2012. 427(2): p. 328-336.

11. Briens, L. and B. Bowden-Green, A comparison of liquid binders for drum granulation of biochar powder. Powder Technology, 2020.

12. Chen, H., C. Mangwandi, and D. Rooney, Production of solid biofuel granules from drum granulation of bio-waste with silicate-based binders. Powder Technology, 2019. 354: p. 231-239.

13. McDonald, M. and J. Hamilton. Recent developments in soluble silicate based binders and coatings. 2007.

14. Albadarin, A.B., et al., Activated lignin-chitosan extruded blends for efficient adsorption of methylene blue. Chemical Engineering Journal, 2017. 307: p. 264-272.

15. Albadarin, A.B., et al., Kinetic and thermodynamics of chromium ions adsorption onto low-cost dolomite adsorbent. Chemical Engineering Journal, 2012. 179: p. 193-202.

16. Mangwandi, C., et al., Optimisation of high shear granulation of multicomponent fertiliser using response surface methodology. Powder Technology, 2013. 238: p. 142-150.

17. Ángeles Martín-Lara, M.a., et al., Sorption of Cr (VI) onto Olive Stone in a Packed Bed Column: Prediction of Kinetic Parameters and Breakthrough Curves. Vol. 136. 2010.

18. Prabhakaran, S.K., K. Vijayaraghavan, and R. Balasubramanian, Removal of Cr(VI) Ions by Spent Tea and Coffee Dusts: Reduction to Cr(III) and Biosorption. Industrial \& Engineering Chemistry Research, 2009. 48(4): p. 2113-2117.

19. Albadarin, A.B. and C. Mangwandi, Mechanisms of Alizarin Red S and Methylene blue biosorption onto olive stone by-product: Isotherm study in single and binary systems. Journal of Environmental Management, 2015. 164: p. 86-93.

20. Baghdadi, Y.N., et al., Growth kinetics of nuclei formed from different binders and powders in vertical cylindrical mixing devices. Chemical Engineering Research and Design, 2018. 132: p. 1070-1081.

21. Banat, F., S. Al-Asheh, and L. Al-Makhadmeh, Evaluation of the use of raw and activated date pits as potential adsorbents for dye containing waters. Process Biochemistry, 2003. 39(2): p. 193-202.

22. Lagergren, S., Zur Theorie der Sogenannten Adsorption Gelöster Stoffe, Kungliga Svenska Vetenskapsakademiens. Handlingar, 1898. 24(4): p. 39.

23. Ho, Y.S. and G. McKay, Pseudo-second order model for sorption processes. Process Biochemistry, 1999. 34(5): p. 451-465.

24. Panda, L., et al., Application of dolochar in the removal of cadmium and hexavalent chromium ions from aqueous solutions. Journal of Hazardous Materials, 2011. 192(2): p. 822-831. 
25. Boparai, H.K., M. Joseph, and D.M. O’Carroll, Kinetics and thermodynamics of cadmium ion removal by adsorption onto nano zerovalent iron particles. Journal of Hazardous Materials, 2011. 186(1): p. 458-465.

26. Ofomaja, A.E., Sorption dynamics and isotherm studies of methylene blue uptake on to palm kernel fibre. Chemical Engineering Journal, 2007. 126(1): p. 35-43.

27. Mangwandi, C., T.A. Kurniawan, and A.B. Albadarin, Comparative biosorption of chromium (VI) using chemically modified date pits (CM-DP) and olive stone (CM-OS): Kinetics, isotherms and influence of co-existing ions. Chemical Engineering Research and Design, 2020. 156: p. 251-262.

28. Bhattacharyya, K.G. and A. Sharma, Kinetics and thermodynamics of Methylene Blue adsorption on Neem (Azadirachta indica) leaf powder. Dyes and Pigments, 2005. 65(1): p. 51-59.

29. Anandkumar, J. and B. Mandal, Adsorption of chromium(VI) and Rhodamine B by surface modified tannery waste: Kinetic, mechanistic and thermodynamic studies. Journal of Hazardous Materials, 2011. 186(2): p. 1088-1096.

30. Karthikeyan, T., S. Rajgopal, and L.R. Miranda, Chromium(VI) adsorption from aqueous solution by Hevea Brasilinesis sawdust activated carbon. Journal of Hazardous Materials, 2005. 124(1): p. 192199.

31. Zhang, H., et al., Hexavalent chromium removal from aqueous solution by algal bloom residue derived activated carbon: Equilibrium and kinetic studies. Journal of hazardous materials, 2010. 181: p. 8018.

32. Albadarin, A.B., et al., Influence of solution chemistry on $\operatorname{Cr}(\mathrm{VI})$ reduction and complexation onto date-pits/tea-waste biomaterials. Journal of Environmental Management, 2013. 114: p. 190-201.

33. Albadarin, A.B., et al., Preliminary investigation of mixed adsorbents for the removal of copper and methylene blue from aqueous solutions. Chemical Engineering Journal, 2014. 255: p. 525-534.

34. El-Shafey, E.I., et al., Preparation and characterization of surface functionalized activated carbons from date palm leaflets and application for methylene blue removal. Journal of Environmental Chemical Engineering, 2016. 4(3): p. 2713-2724.

35. Wang, P., et al., Kinetics and thermodynamics of adsorption of methylene blue by a magnetic graphene-carbon nanotube composite. Applied Surface Science, 2014. 290: p. 116-124. 
Table1: Langmuir and Freundlich adsorption isotherm constants for adsorption of chromium (VI) and methylene blue on compost granules with different sodium silicate content.

\begin{tabular}{lccllll}
\hline Sample & \multicolumn{2}{c}{$\begin{array}{c}\text { Chromium (VI) } \\
\text { Langmuir constants }\end{array}$} & \multicolumn{3}{c}{$\begin{array}{c}\text { Methylene blue dye } \\
\text { Freundlich constants }\end{array}$} \\
\cline { 2 - 7 } & $Q_{\max }\left(\mathrm{mg} \mathrm{g}^{-1}\right)$ & $b\left(\mathrm{~L} \mathrm{mg}^{-1}\right)$ & $R^{2}$ & $1 / n$ & $k_{f}$ & $R^{2}$ \\
\hline s0 & 73.37 & 0.61 & 0.81 & $1.36 \mathrm{E}-03$ & 4.60 & 0.97 \\
s1 & 65.43 & 0.53 & 0.80 & $3.46 \mathrm{E}-09$ & 9.73 & 0.98 \\
s3 & 53.70 & 0.61 & 0.75 & $7.43 \mathrm{E}-02$ & 1.82 & 0.99 \\
s5 & 64.09 & 0.32 & 0.87 & $7.31 \mathrm{E}-02$ & 1.69 & 0.90 \\
\hline
\end{tabular}




\begin{tabular}{|c|c|c|c|c|c|c|c|c|c|c|c|c|c|}
\hline \multirow[t]{3}{*}{ Sample } & \multirow{3}{*}{$\begin{array}{l}\text { Temp. } \\
{ }^{\circ} \mathrm{C}\end{array}$} & \multicolumn{6}{|c|}{ Chromium VI } & \multicolumn{6}{|c|}{ Methylene Blue } \\
\hline & & \multicolumn{3}{|c|}{ Pseudo $1^{\text {st }}$ order } & \multicolumn{3}{|c|}{ Pseudo $2^{\text {nd }}$ order } & \multicolumn{3}{|c|}{ Pseudo $1^{\text {st }}$ order } & \multicolumn{3}{|c|}{ Pseudo $2^{\text {nd }}$ order } \\
\hline & & $\begin{array}{l}\mathrm{k}_{1} \times 10^{-4} \\
\left(\min ^{-1}\right)\end{array}$ & $R^{2}$ & $\begin{array}{l}\mathrm{Qmax} \\
(\mathrm{mmol} / \mathrm{g})\end{array}$ & $\begin{array}{l}\mathrm{k}_{1} \quad \mathrm{x}_{10}^{-6} \\
(\mathrm{~g} / \mathrm{mmol} \mathrm{min})\end{array}$ & $R^{2}$ & $\begin{array}{l}\mathrm{Q}_{\max } \\
(\mathrm{mmol} / \mathrm{g})\end{array}$ & $\begin{array}{l}\mathrm{k}_{1} \times 10^{-4} \\
\left(\mathrm{~min}^{-1}\right)\end{array}$ & $R^{2}$ & $\begin{array}{l}\mathrm{Qmax} \\
(\mathrm{mmol} / \mathrm{g})\end{array}$ & $\begin{array}{l}\mathrm{k}_{2} \times 10^{-6} \\
(\mathrm{~g} / \mathrm{mmol} \mathrm{min})\end{array}$ & $R^{2}$ & $\begin{array}{l}\mathrm{Q}_{\max } \\
(\mathrm{mmol} / \mathrm{g})\end{array}$ \\
\hline \multirow{4}{*}{ S0 } & 25 & 1.10 & 0.99 & 1.13 & 0.66 & 0.99 & 1.91 & 2.02 & 0.98 & 0.121 & 3.05 & 0.98 & 0.169 \\
\hline & 30 & 1.52 & 0.99 & 0.99 & 1.40 & 0.99 & 1.58 & 3.85 & 0.98 & 0.112 & 8.39 & 0.98 & 0.141 \\
\hline & 40 & 7.23 & 0.97 & 0.78 & 19.40 & 0.97 & 0.89 & 7.66 & 0.97 & 0.104 & 25.80 & 0.98 & 0.118 \\
\hline & 60 & 1.79 & 0.99 & 0.78 & 44.90 & 0.98 & 0.86 & 28.60 & 0.98 & 0.112 & 82.90 & 0.98 & 0.122 \\
\hline \multirow{4}{*}{ S3 } & 25 & 1.03 & 0.99 & 1.19 & 0.59 & 0.99 & 2.02 & 3.27 & 0.99 & 0.092 & 7.69 & 0.99 & 0.120 \\
\hline & 30 & 1.62 & 0.99 & 0.97 & 1.36 & 0.99 & 1.51 & 4.08 & 0.99 & 0.092 & 10.70 & 0.99 & 0.116 \\
\hline & 40 & 7.14 & 0.97 & 0.78 & 18.90 & 0.97 & 0.89 & 6.13 & 0.97 & 0.096 & 18.80 & 0.98 & 0.114 \\
\hline & 60 & 17.8 & 0.99 & 0.78 & 44.30 & 0.97 & 0.86 & 17.60 & 0.97 & 0.111 & 47.20 & 0.98 & 0.125 \\
\hline
\end{tabular}


Table 3 : Thermodynamic parameters for the biosorption of of Cr(VI) and MB onto SO and S3 granules.

\begin{tabular}{|c|c|c|c|c|c|c|c|c|}
\hline \multirow[t]{2}{*}{ Material } & \multirow[t]{2}{*}{ Adsorbate } & \multirow{2}{*}{$\begin{array}{l}\text { Activation } \\
\text { energy } \\
{[\mathrm{kJ} / \mathrm{mol}]}\end{array}$} & \multirow[t]{2}{*}{$\Delta \mathrm{H}(\mathrm{kJ} / \mathrm{mol})$} & \multirow[t]{2}{*}{$\Delta \mathrm{S}(\mathrm{kJ} / \mathrm{mol} \mathrm{K})$} & \multicolumn{4}{|c|}{$\Delta \mathrm{G}(\mathrm{kJ} / \mathrm{mol} \mathrm{K})$} \\
\hline & & & & & $25^{\circ} \mathrm{C}$ & $30^{\circ} \mathrm{C}$ & $40^{\circ} \mathrm{C}$ & $60^{\circ} \mathrm{C}$ \\
\hline \multirow[t]{2}{*}{ S0 Granules } & $\mathrm{Cr}(\mathrm{VI})$ & 56.2 & 95.0 & 0.3 & 1.79 & 1.29 & -6.11 & -8.37 \\
\hline & $\mathrm{MB}$ & 40.6 & 43.4 & 0.1 & 8.03 & 6.67 & 5.35 & 3.61 \\
\hline \multirow[t]{2}{*}{ S3 Granules } & $\mathrm{Cr}(\mathrm{VI})$ & 57.4 & 97.8 & 0.3 & 0.76 & 0.076 & -4.28 & -10.2 \\
\hline & $\mathrm{MB}$ & 21.8 & 44.4 & 0.1 & 7.00 & 6.70 & 5.28 & 2.75 \\
\hline
\end{tabular}


Table 4 Review of literature for adsorption of chromium for various industrial wastes.

\begin{tabular}{l|c|c|c}
\hline \multirow{2}{*}{ Adsorbent material } & \multicolumn{2}{|c|}{ Adsorbate } & Reference \\
\cline { 2 - 3 } & $\mathrm{Cr}(\mathrm{VI})[\mathrm{mg} / \mathrm{g}]$ & $\mathrm{MB}[\mathrm{mg} / \mathrm{g}]$ & \\
\hline Composite granules & $64-73$ & $29-36$ & Current study \\
Tannery waste & 177 & - & {$[30]$} \\
Clarified sludge & 26.31 & - & \\
Chemical modified pit & 53.31 & - & {$[28]$} \\
Dolochar from sponge iron industry & 5.21 & - & {$[25]$} \\
Teawaste & 107.8 & - & {$[33]$} \\
$\begin{array}{l}\text { Date pits } \\
\text { Neem leaf powder }\end{array}$ & -66.02 & - & {$[22]$} \\
Teawaste \& Dolomite & - & 150.4 & {$[29]$} \\
$\begin{array}{l}\text { Magnetic graphene- carbon nonotube } \\
\text { composite }\end{array}$ & - & 65.79 & {$[36]$} \\
$\begin{array}{l}\text { Activated lignin-chitosan composite } \\
\text { extrudates }\end{array}$ & - & 36.3 & {$[14]$} \\
functionalized activated carbon from & - & 34.70 & {$[35]$} \\
date palm & & & \\
\hline
\end{tabular}




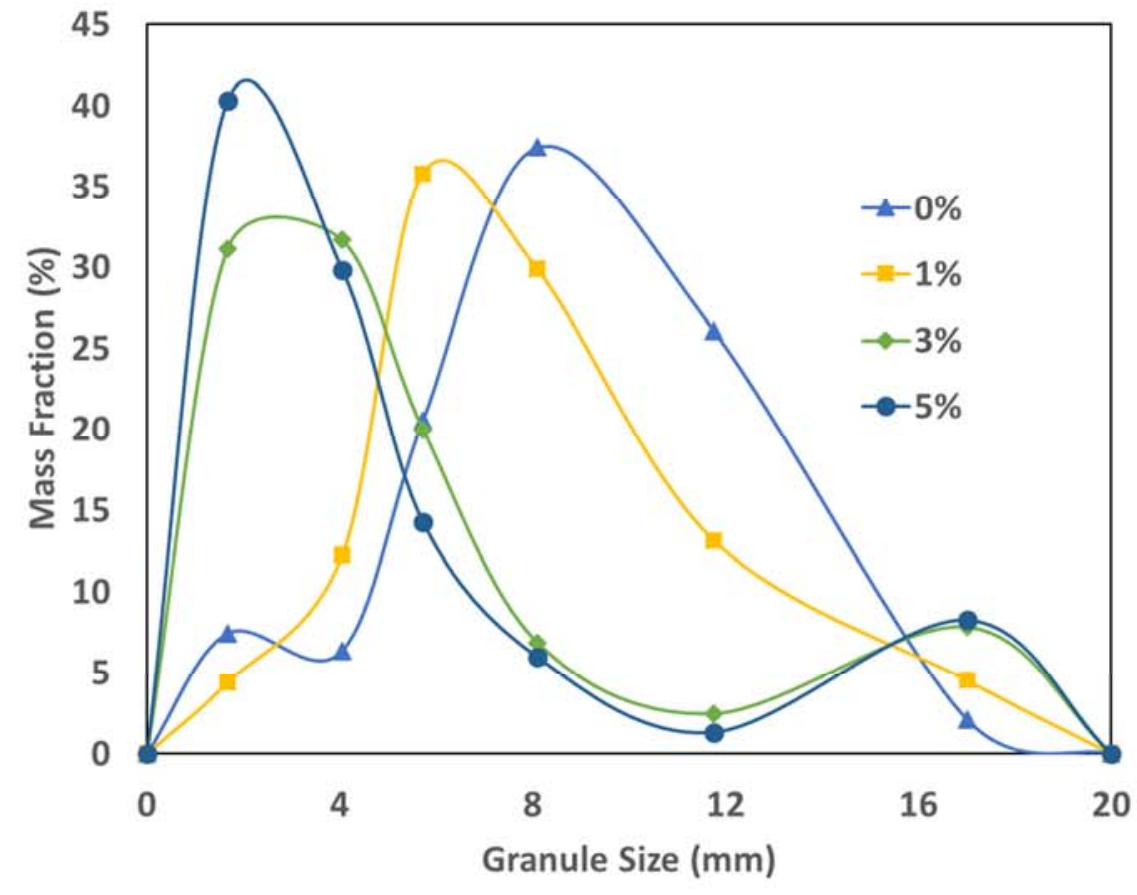

(a)

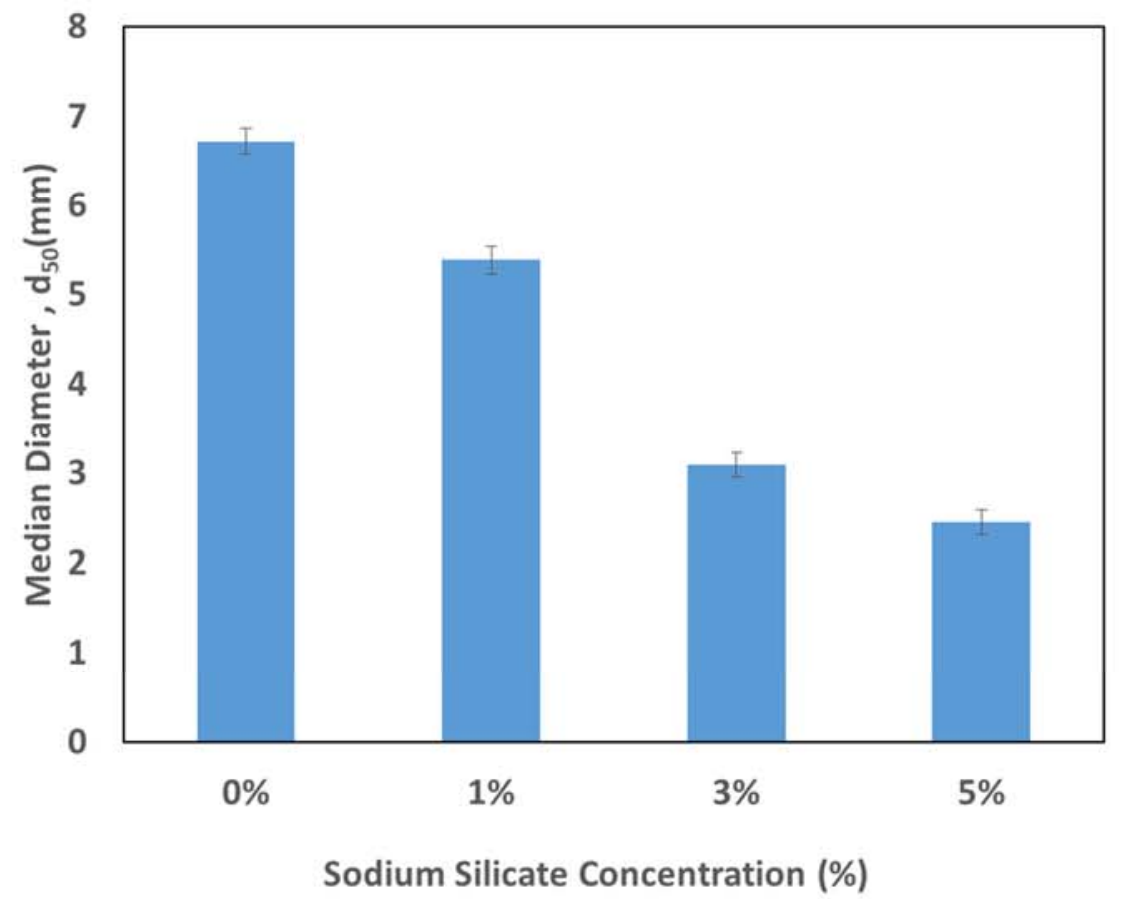

(b)

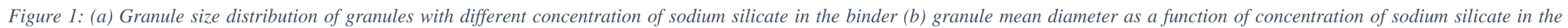
binder. 


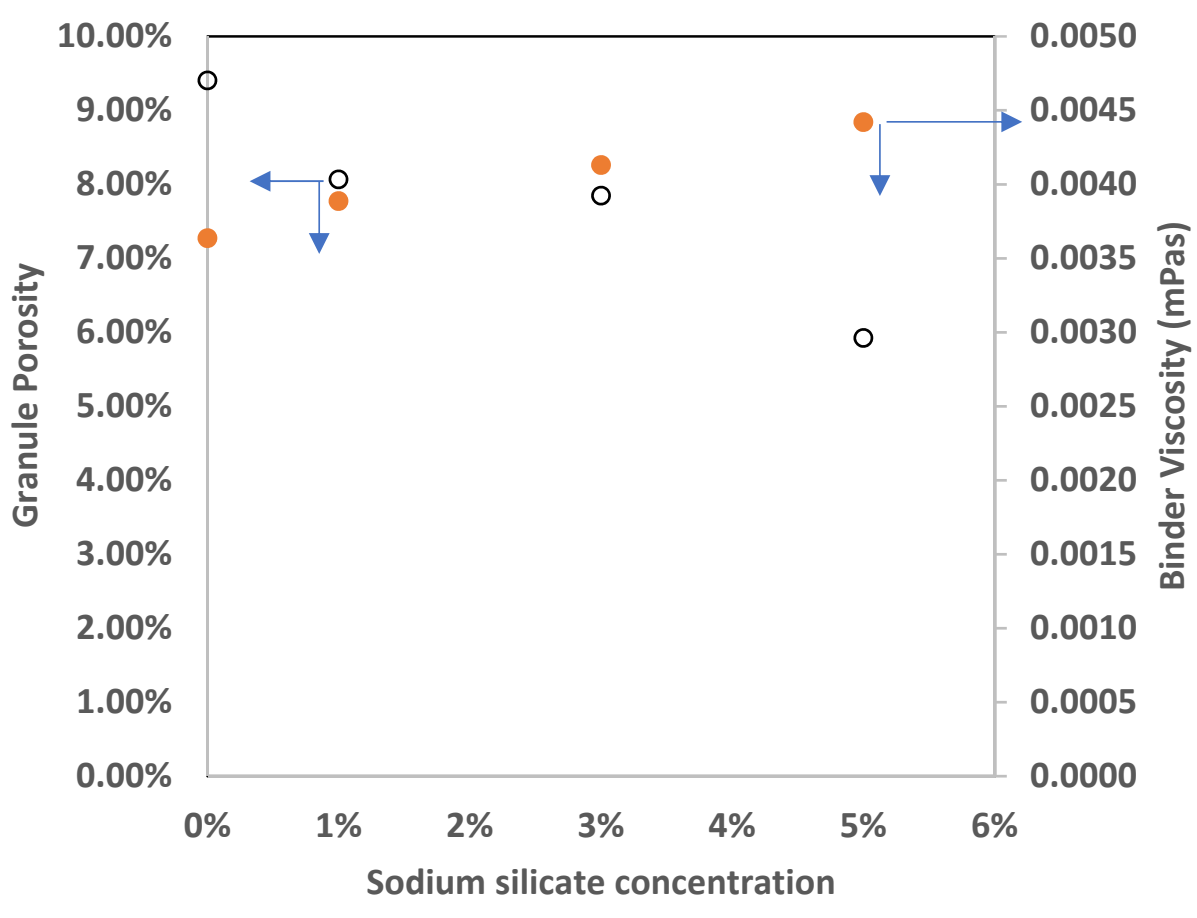

(a)

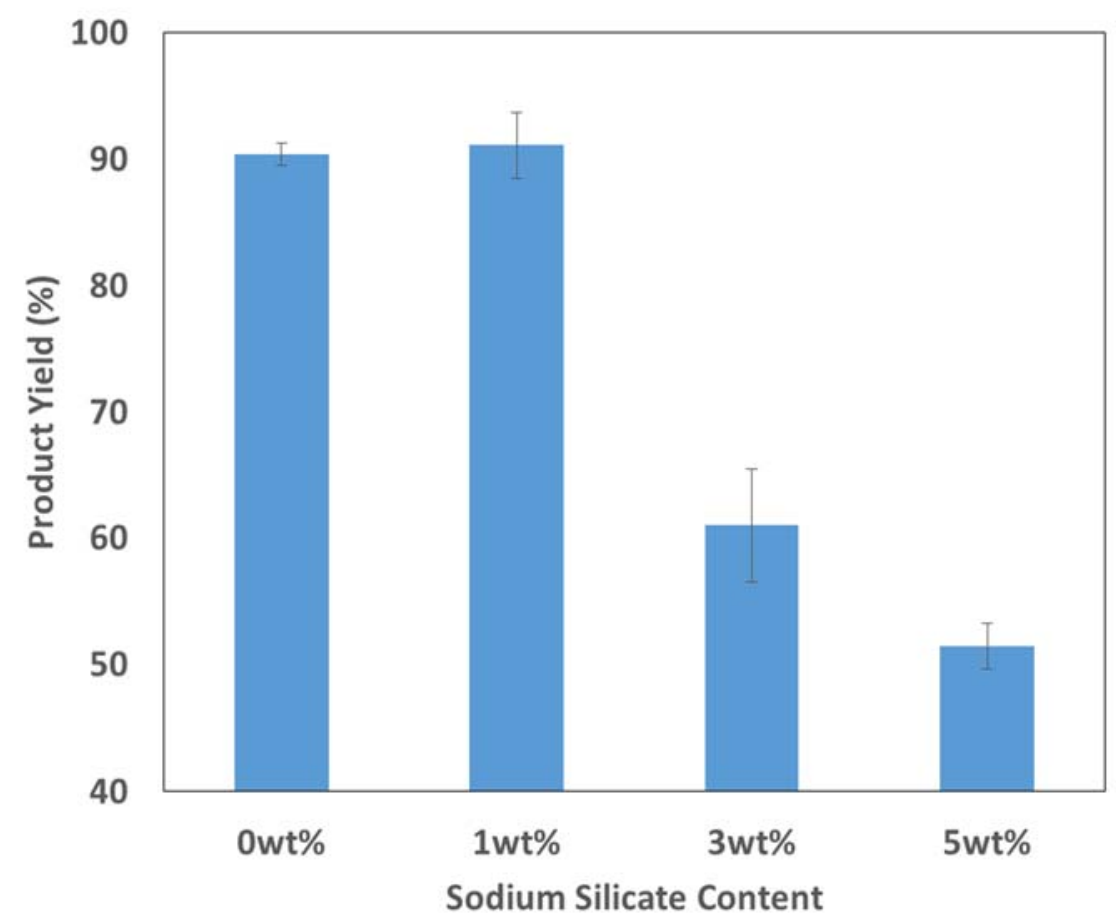

(b)

Figure 2:(a)Binder viscosity and granule porosity as a function of concentration of sodium silicate. (b) Percentage yield of granules in the desired size range as a function of concentration of sodium silicate in the binder. The desired size range is 4.75 to $14 \mathrm{~mm}$. 


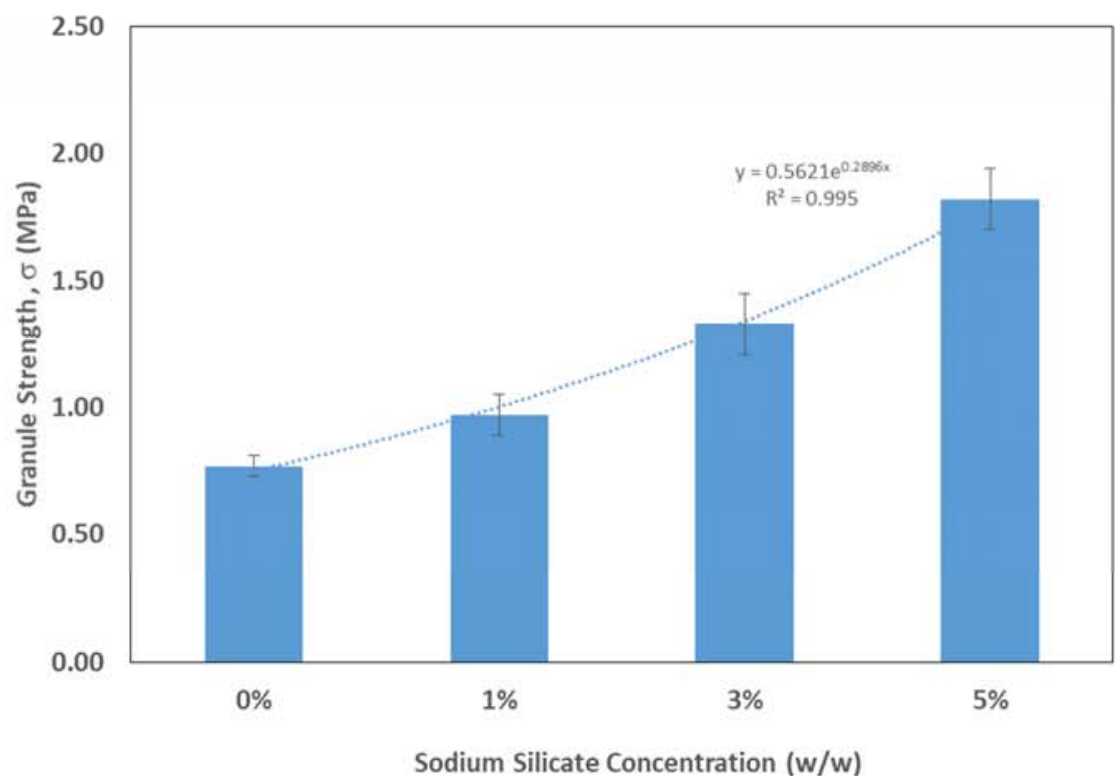

(a)

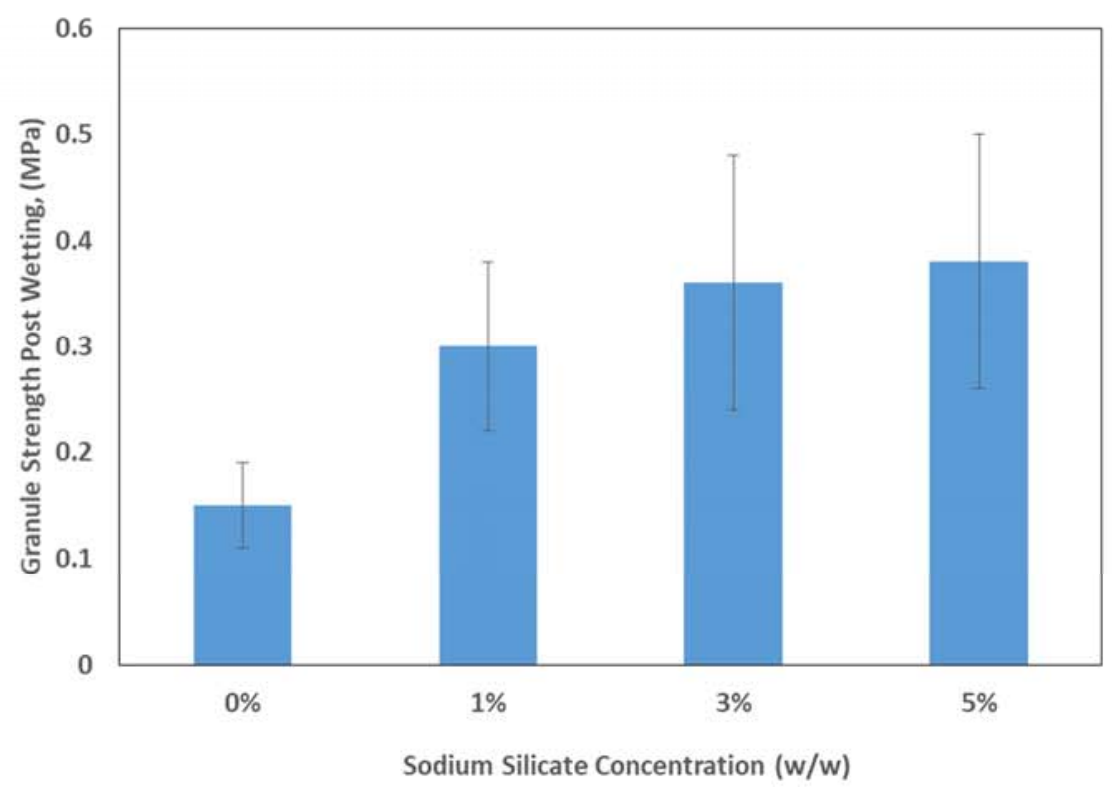

(b)

Figure 3: (a) Effect of sodium silicate concentration on granule strength (b) Granule strength after $24 \mathrm{hr}$ soaking in water 

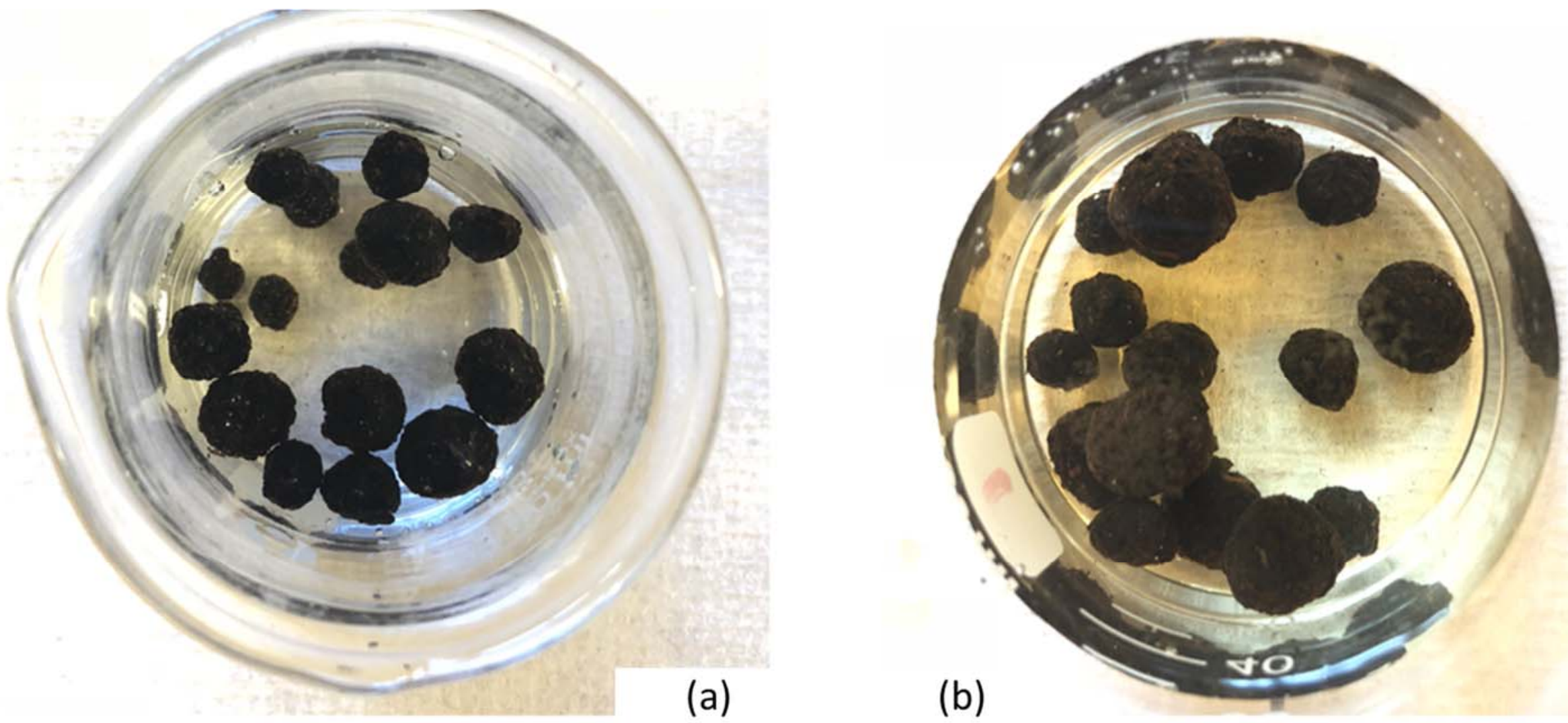

Figure 4:Images of compost granules after immersion in water (a) 1 min and (b) 24 hours 


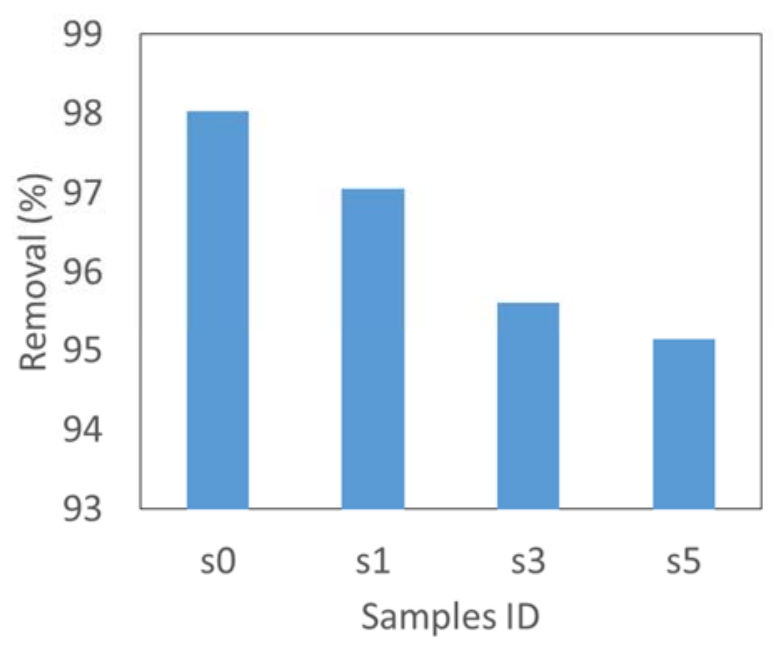

(a)

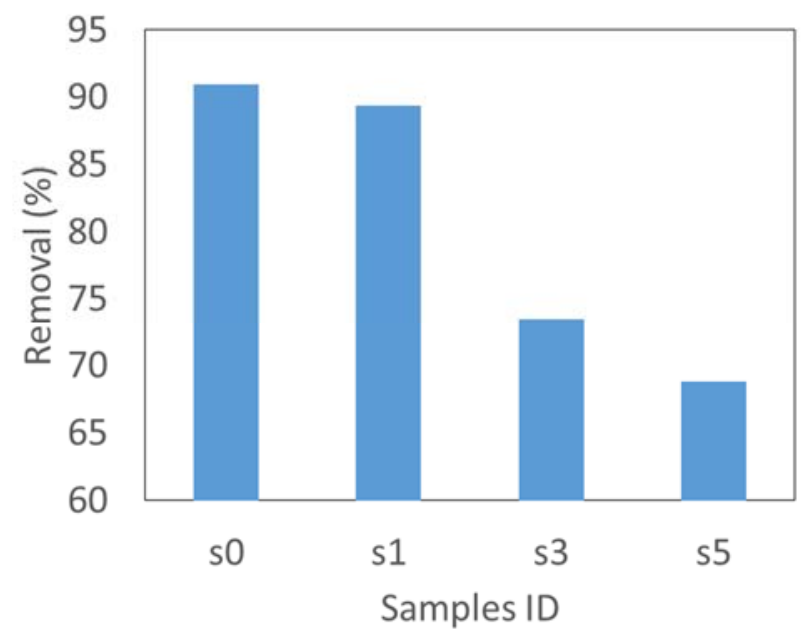

(c)

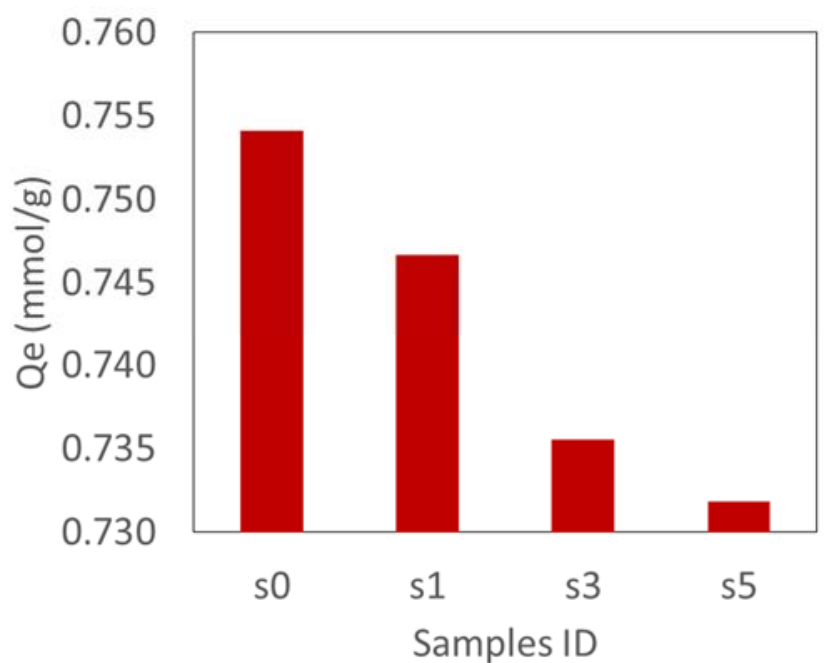

(b)

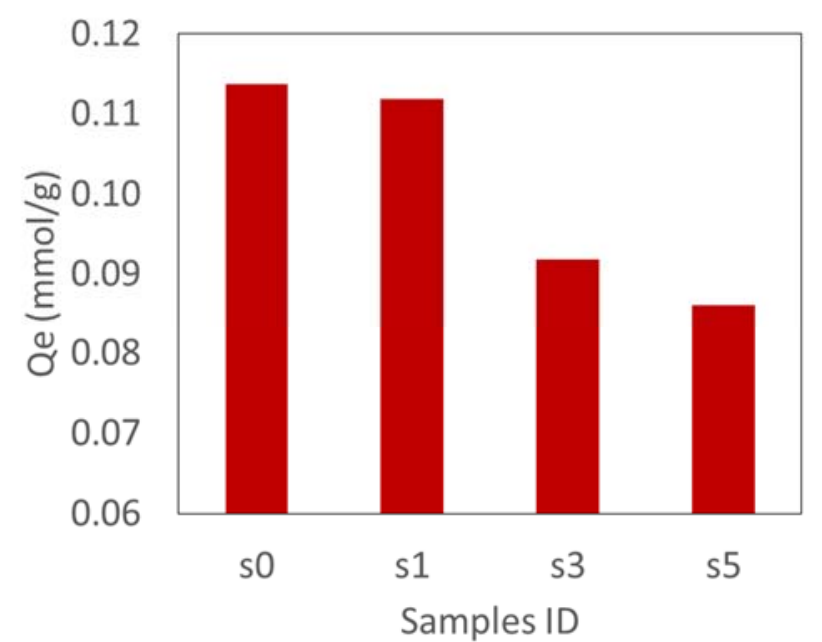

(d)

Figure 5: (a) and (b) effect of sodium silicate binder concentration of removal efficiency of chromium (VI) and its adsorption capacity (multiplied by 100). (c) and (d) effect of sodium silicate binder concentration of removal efficiency of Methylene Blue and its adsorption capacity.. 


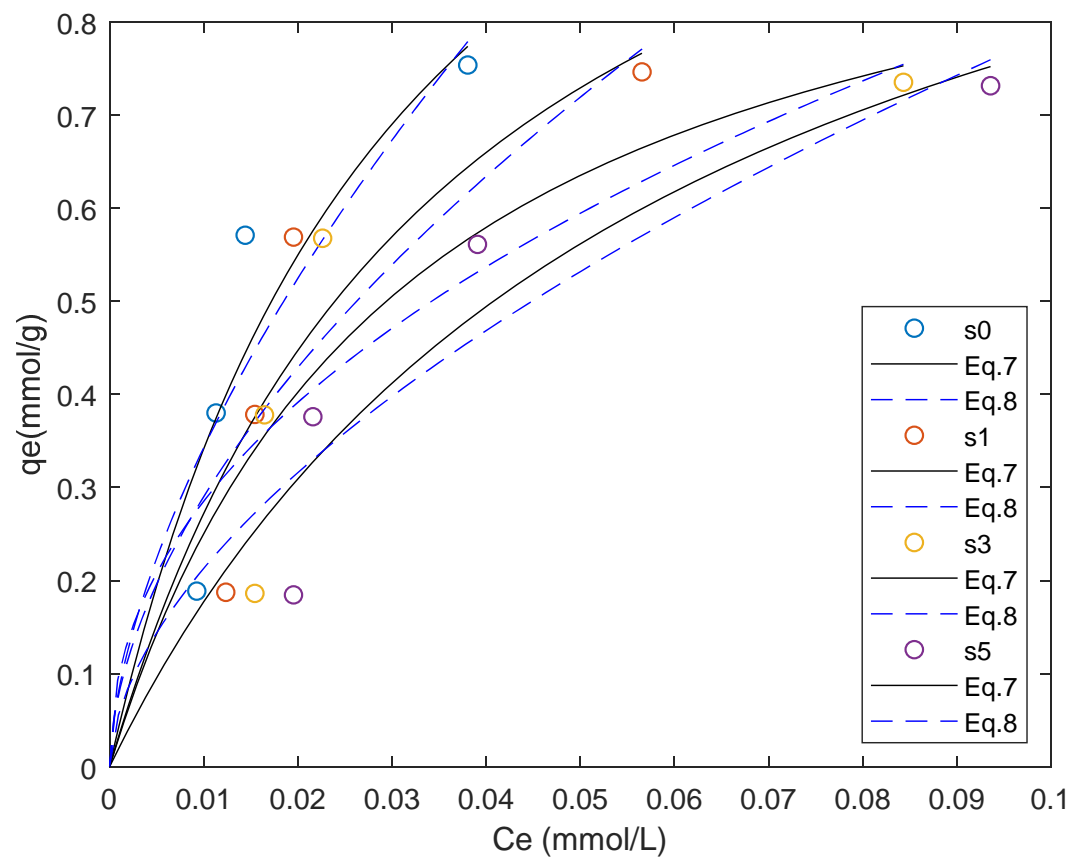

(a)

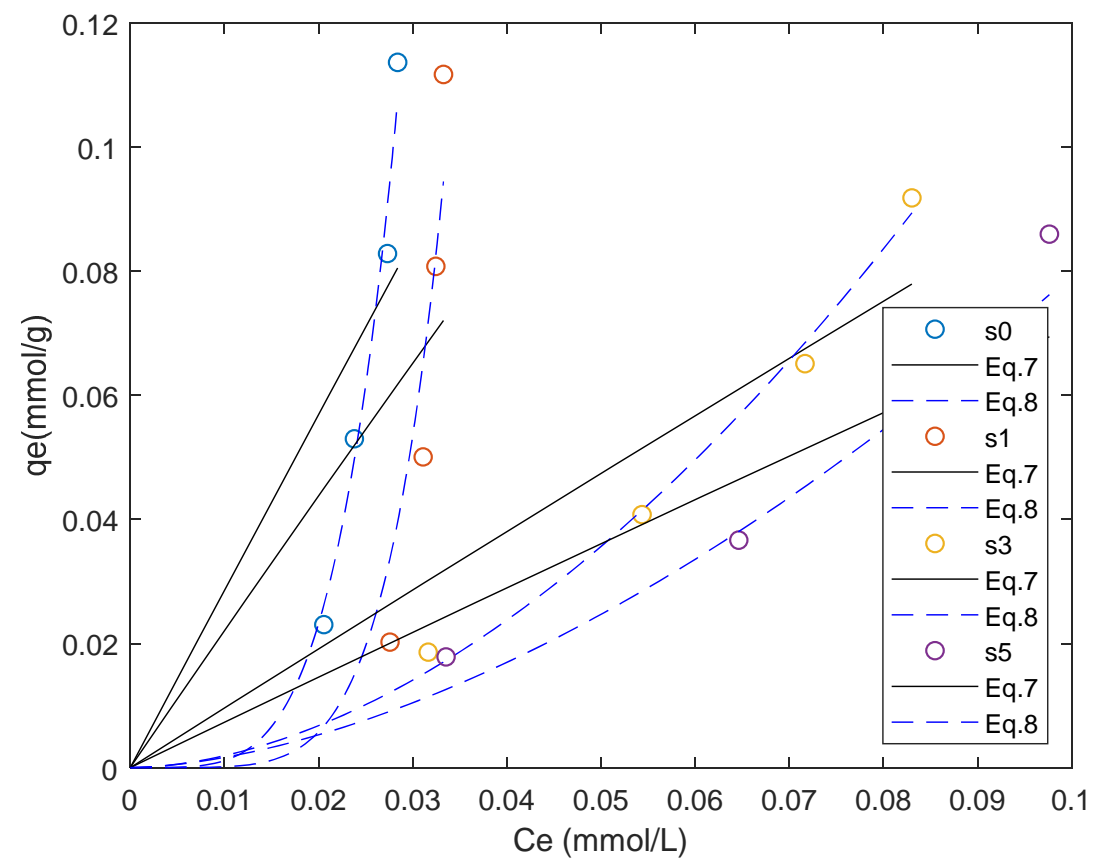

(b)

Figure 6: Isotherms for adsorption of Cr(VI) (a) and methylene blue dye (b) onto granules with different concentrations of sodium silicate binder. The continuous and dashed lines in (a) and (b) are non-linear regression fits of the Langmuir and Freundlich isotherms respectively. 

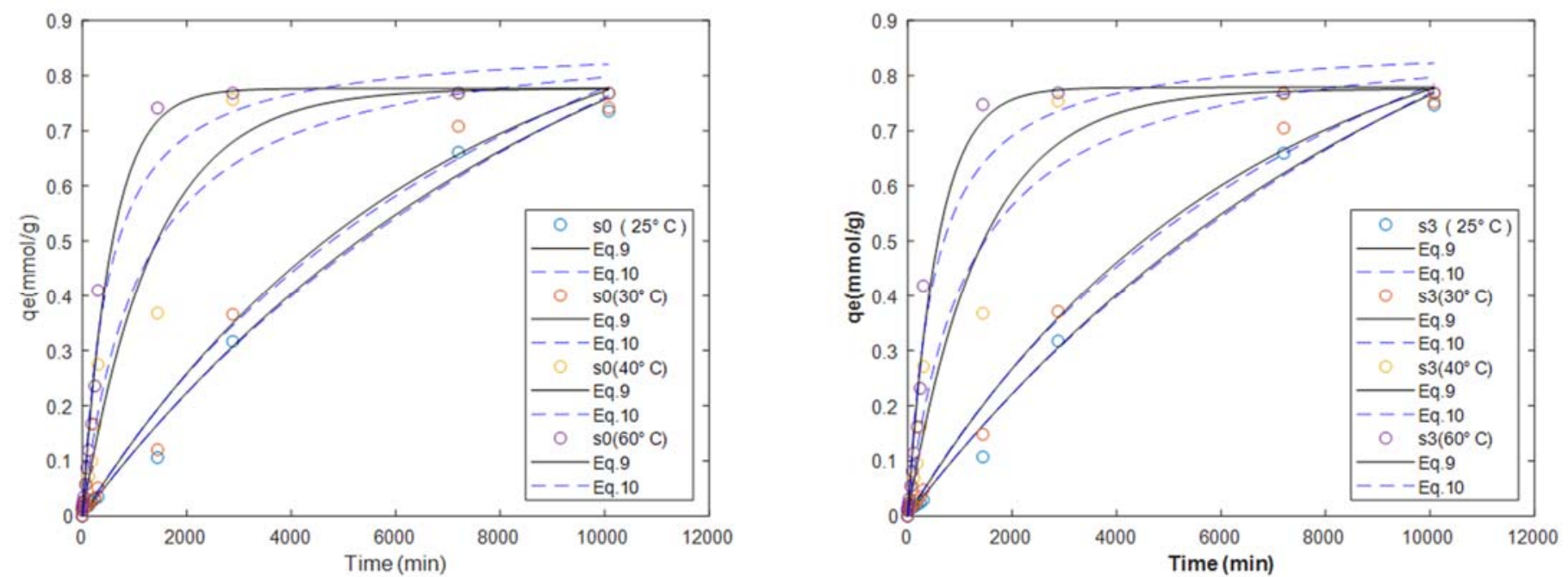

(a)

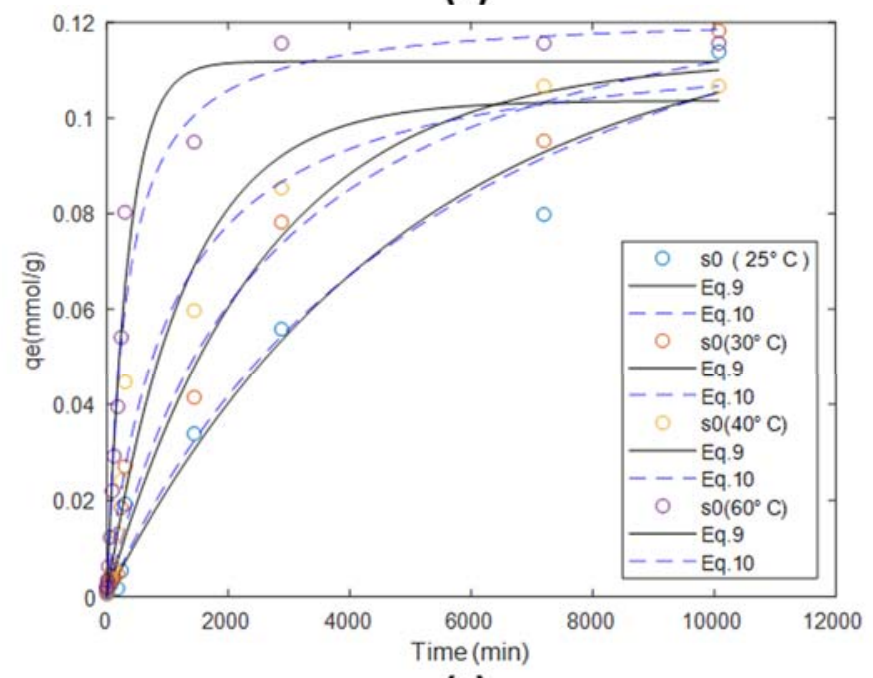

(c)

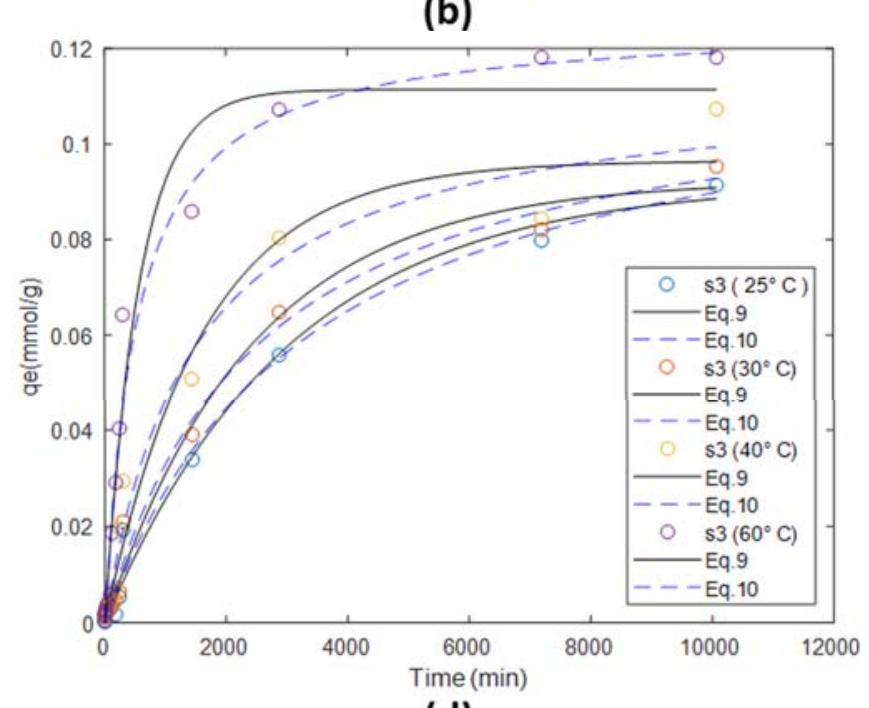

(d)

Figure 7 : Kinetics of Chromium removal by (a) s0 compost granules. (b) s3 compost granules at different temperatures. (c) and (d) show the remova kinetics of MB by S0 and S3 granuules respectively. The continuous and the dashed lines in the plot represent the Pseudo $1^{\text {st }}$ order model represents the Pseudo $2^{\text {nd }}$ order fits. 


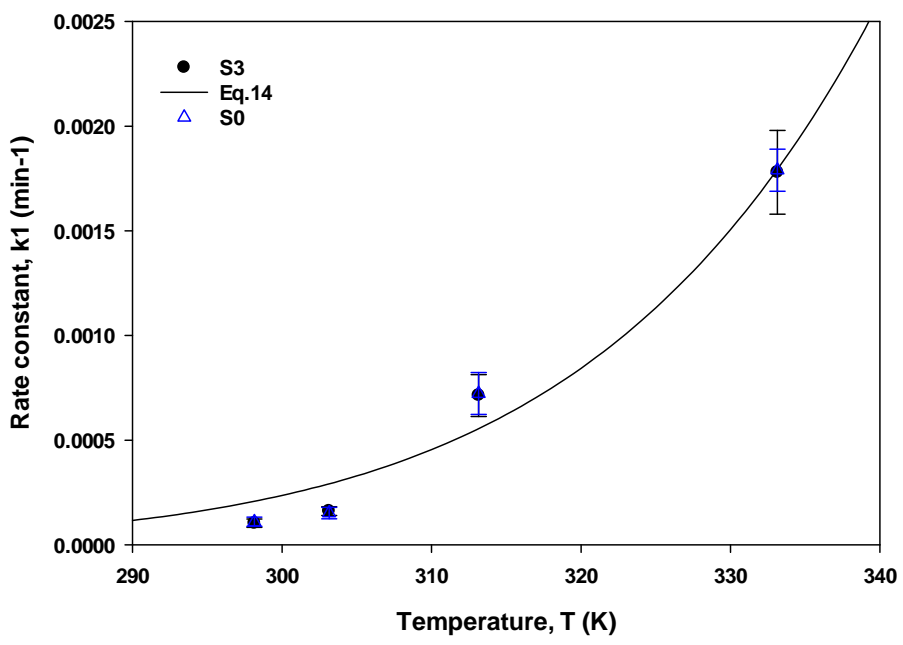

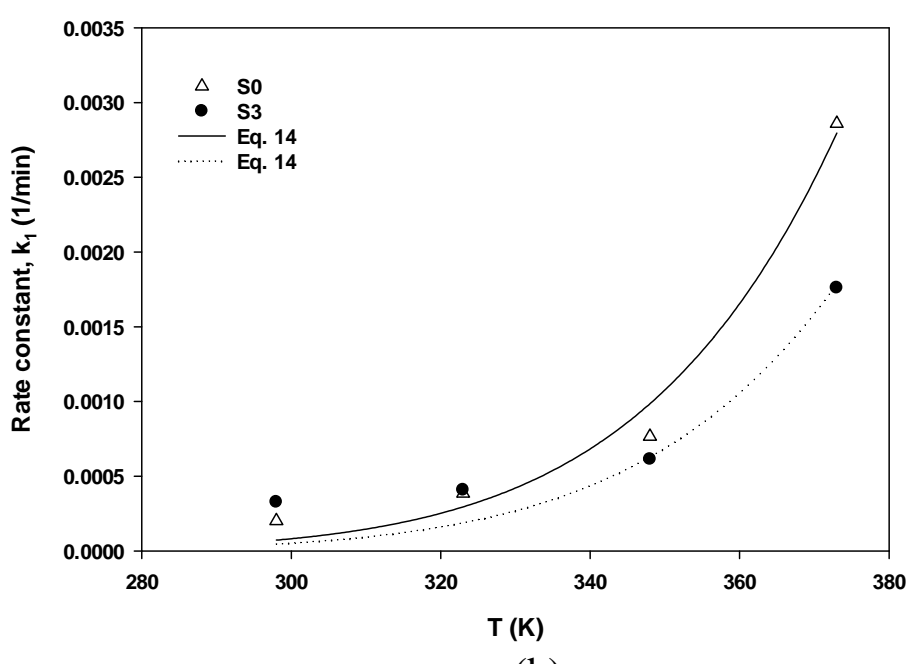

(b)

Figure 8:adsorption rate constant as function of temperature (a) removal of $\mathrm{Cr}(\mathrm{VI})$ (b) removal of Methylene blue dye with biomass granules. 
